\title{
Near-infrared spectroscopy in schizophrenia: a possible biomarker for predicting clinical outcome and treatment
} response

\author{
Shinsuke Koike ${ }^{1,2}$,, Yukika Nishimura ${ }^{2}$, Ryu Takizawa ${ }^{2,3}$, Noriaki Yahata ${ }^{4}$ and Kiyoto Kasai ${ }^{2}$ \\ 1 Office for Mental Health Support, Division for Counseling and Support, The University of Tokyo, Tokyo, Japan \\ ${ }^{2}$ Department of Neuropsychiatry, Graduate School of Medicine, The University of Tokyo, Tokyo, Japan \\ ${ }^{3}$ Social, Genetic and Developmental Psychiatry Centre, Institute of Psychiatry, King's College London, London, UK \\ ${ }^{4}$ Department of Youth Mental Health, Graduate School of Medicine, The University of Tokyo, Tokyo, Japan
}

\section{Edited by:}

Stefan Borgwardt, University of

Basel, Switzerland

\section{Reviewed by:}

Takahiro A. Kato, Kyushu University, Japan

Masato Fukuda, Gunma University, Japan

${ }^{*}$ Correspondence:

Shinsuke Koike, Office for Mental Health Support, Division for

Counseling and Support, The University of Tokyo, 7-3-1 Hongo,

Bunkyo-ku, Tokyo 113-0033, Japan e-mail: skoike-tky@umin.ac.jp
Functional near-infrared spectroscopy (fNIRS) is a relatively new technique that can measure hemoglobin changes in brain tissues, and its use in psychiatry has been progressing rapidly. Although it has several disadvantages (e.g., relatively low spatial resolution and the possibility of shallow coverage in the depth of brain regions) compared with other functional neuroimaging techniques (e.g., functional magnetic resonance imaging and positron emission tomography), fNIRS may be a candidate instrument for clinical use in psychiatry, as it can measure brain activity in naturalistic position easily and non-invasively. fNIRS instruments are also small and work silently, and can be moved almost everywhere including schools and care units. Previous fNIRS studies have shown that patients with schizophrenia have impaired activity and characteristic waveform patterns in the prefrontal cortex during the letter version of the verbal fluency task, and part of these results have been approved as one of the Advanced Medical Technologies as an aid for the differential diagnosis of depressive symptoms by the Ministry of Health, Labor and Welfare of Japan in 2009, which was the first such approval in the field of psychiatry. Moreover, previous studies suggest that the activity in the frontopolar prefrontal cortex is associated with their functions in chronic schizophrenia and is its next candidate biomarker. Future studies aimed at exploring fNIRS differences in various clinical stages, longitudinal changes, drug effects, and variations during different task paradigms will be needed to develop more accurate biomarkers that can be used to aid differential diagnosis, the comprehension of the present condition, the prediction of outcome, and the decision regarding treatment options in schizophrenia. Future fNIRS researches will require standardized measurement procedures, probe settings, analytical methods and tools, manuscript description, and database systems in an fNIRS community.

Keywords: near-infrared spectroscopy, verbal fluency task, biological markers, early intervention, clinical outcome

\section{INTRODUCTION}

Techniques that allow the easier and less invasive measurement of brain structure and activity, such as magnetic resonance imaging (MRI), functional MRI, and positron emission tomography (PET), have progressed rapidly over the past 20 years. There has been considerable expectation regarding the clinical application of neuroimaging techniques to psychological conditions and psychiatric illnesses $(1,2)$. Biological markers measured using neuroimaging instruments would clarify the pathophysiological features of psychiatric disorders, inform patients and family members regarding their actual conditions, and improve general impression of psychiatric disorders, by more easily giving the explanation of their conditions and discussing their assumed prognoses.

Functional near-infrared spectroscopy (fNIRS) is a functional brain imaging tool that can measure hemoglobin changes over the surface of the brain easily and non-invasively (Figure 1) (3-5). fNIRS technique was found in 1977 (6), and has been applied to measure brain hemodynamic activity through the scalp $(7,8)$. The release of commercial fNIRS machines that are small, movable, and work silently during the last decade (Figure 1B) has allowed the progress of fNIRS research in the field of psychiatry (9). In 2012, more than 100 studies were published on this subject; among these, about 20 articles pertained to the field of psychiatry (9). Part of the results of those fNIRS studies has been approved as one of the Advanced Medical Technologies as an aid for the differential diagnosis of depressive symptoms by the Ministry of Health, Labor and Welfare of Japan in 2009 (10-12), as the presence of different characteristic waveform patterns in the prefrontal cortex (PFC) during a verbal fluency task (VFT) has been reported among patients with major depressive illness $(4,12-17)$, bipolar disorder $(12,13)$, and schizophrenia $(4,5,12)$. This was the first such approval in the field of psychiatry in Japan (see the "Application to supplementary diagnostic tool for psychiatric disorders" subsection). Here, we reviewed fNIRS research that focused on schizophrenia, which 


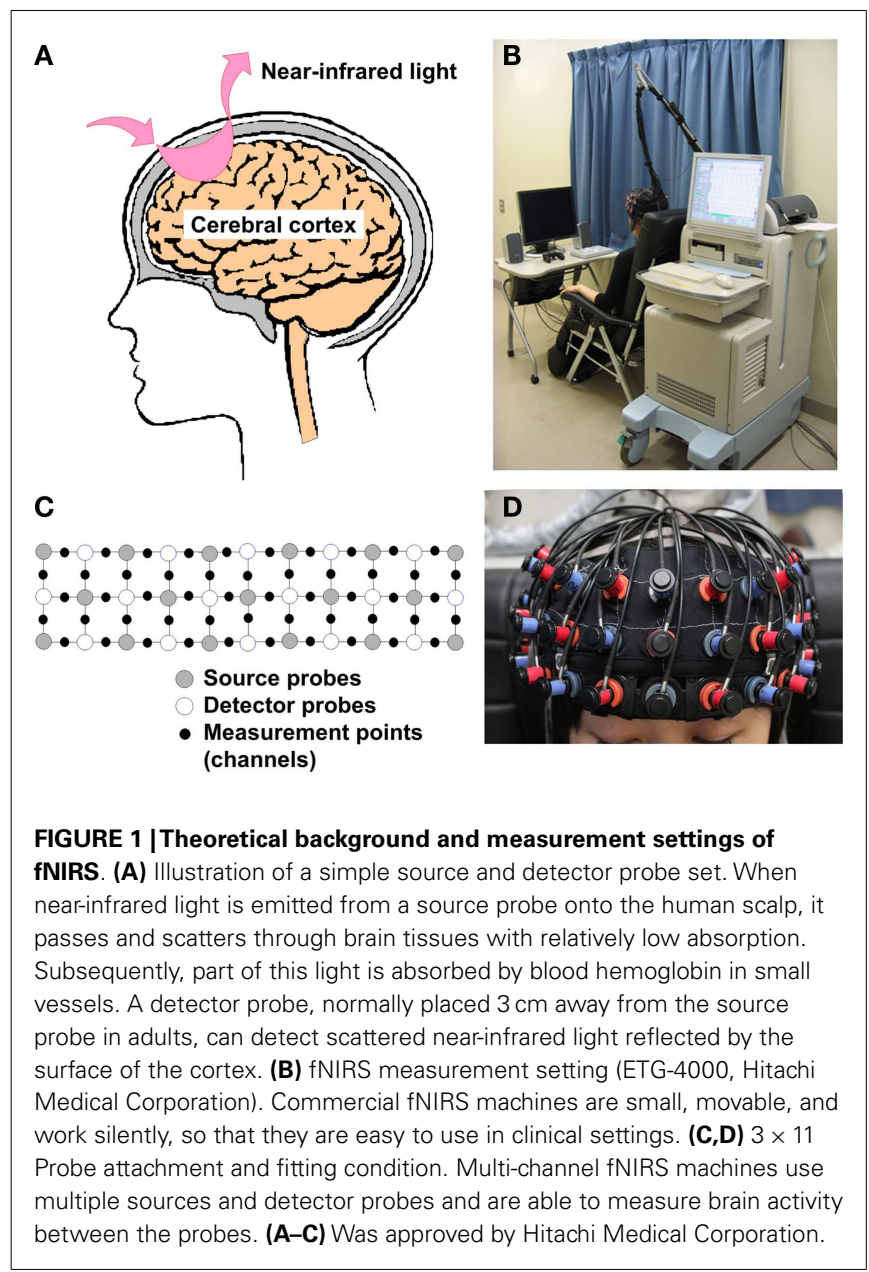

is currently the most published topic in the application of fNIRS in the field of psychiatry, and address future investigations that are needed for the clinical application of this technique as an aid for the differential diagnosis, comprehension of present conditions, prediction of outcome, and decision regarding treatment options in schizophrenia.

\section{PRINCIPLES OF BRAIN ACTIVITY MEASUREMENT USING NEAR-INFRARED LIGHT \\ THEORETICAL BACKGROUND OF THE MEASUREMENT OF BRAIN ACTIVITY USING FNIRS INSTRUMENTS}

Near-infrared light, especially that with a wavelength of 650$1000 \mathrm{~nm}$, has characteristics that include a relatively high absorption through hemoglobin, as well as a relatively high penetration through bone and skin, compared with light with other wavelengths. The emission of near-infrared light from a source probe on the human scalp leads to its passing and scattering through brain tissues with relatively low absorption, followed by the absorption of part of this light by blood hemoglobin in small vessels $(<1 \mathrm{~mm})$ (18). A detector probe, which is normally placed $3 \mathrm{~cm}$ away from the source probe in adults, can detect scattered near-infrared light that is reflected by the surface of the cortex (Figure 1A). Therefore, the region located between the source and the detector probes is generally set as a measurement area that is often called a "channel" (Figure 1C). fNIRS instruments can measure oxygenated hemoglobin $\left(\mathrm{O}_{2} \mathrm{Hb}\right)$ and deoxygenated hemoglobin $(\mathrm{HHb})$, as well as total hemoglobin ( $\mathrm{tHb}$ ) by summing up $\mathrm{O}_{2} \mathrm{Hb}$ and $\mathrm{HHb}$, by using near-infrared light with two or more different wavelengths that are slightly different from the absorption rates of $\mathrm{O}_{2} \mathrm{Hb}$ and $\mathrm{HHb}$. In accordance with light manipulation, fNIRS instruments are roughly divided into three types: continuous wave $(\mathrm{CW})$, frequency domain (FD), and time domain (TD) instruments. Although CW-type fNIRS machines are unable to measure absolute hemoglobin concentration in tissues, they are relatively small, have low installation and maintenance costs, and are able to perform measurements at a high sampling rate compared with FD- and TD-type fNIRS machines (18). Therefore, recent clinical studies have used CW-type fNIRS machines $(19,20)$. The theoretical details of all types of fNIRS instruments were reviewed elsewhere $(18,20,21)$.

\section{ADVANTAGES AND DISADVANTAGES OF FNIRS COMPARED WITH OTHER FUNCTIONAL IMAGING INSTRUMENTS}

The advantages and disadvantages of CW-type fNIRS compared with other functional imaging instruments (fMRI, PET, and EEG) are shown in Table 1. fNIRS has the following advantages: (1) non-invasiveness, which allows repetitive measurements, even in infants (21, 22); (2) easy setting; (3) small size and portability; (4) high temporal resolution compared with fMRI and PET $(18,20)$; (5) possibility of performing measurements in a non-restrained position, such that participants can sit on a chair, talk, and move their hands; and (6) possibility of relatively easily combining measurements with other neuroimaging techniques, such as EEG (23, 24), MRI (25-30), PET (31-33), and magnetoencephalography (MEG) $(34,35)$. Conversely, fNIRS has the following disadvantages: (1) low spatial resolution $(10-30 \mathrm{~mm})$; (2) possibility of performing measurements only at the surface of the cortex; (3) inability to measure absolute hemoglobin value (CW-type); and (4) the data obtained can be influenced by scalp, muscle, skull, and cerebrospinal fluid factors in addition to hemodynamic changes in the cortex (20).

Other than task-related hemoglobin changes derived from neural activities under neurovascular coupling, fNIRS signals vary depending on task-related blood pressure changes and skin blood flow, as well as spontaneous brain activity related to heart rate, respiration, and physiological oscillations (20, 21). Simultaneous measurements by fNIRS and pulse Doppler sonography or by fNIRS with different probe distances [e.g., shallow $(5 \mathrm{~mm})$ and deep $(30 \mathrm{~mm})$ ] allow the distinction of fNIRS signals from the cortex from those of other brain tissues. A study based on fNIRS with different probe distances and laser Doppler velocimetry showed that hemoglobin changes from the cortex during the VFT may contain only $6 \%$ of fNIRS data in the PFC, and that most signal changes may arise from changes in skin blood flow (36). The results OPF simultaneous fNIRS, fMRI, MR angiography, and peripheral physiological measurements suggested that task-evoked sympathetic arterial vasoconstriction affected fNIRS signal changes substantially (37). However, a subsequent study in which simultaneous measurements using multiple fNIRS probe 
Table 1 | Comparison of CW-type fNIRS machines with other neuroimaging tools.

\begin{tabular}{|c|c|c|c|c|c|c|}
\hline & & fNIRS & fMRI & PET & EEG & MEG \\
\hline \multirow[t]{5}{*}{$\begin{array}{l}\text { Theoretical } \\
\text { background }\end{array}$} & Signal property & $\begin{array}{l}\text { Scattered } \\
\text { near-infrared light }\end{array}$ & $\begin{array}{l}\text { Magnetic } \\
\text { property }\end{array}$ & $\begin{array}{l}\text { Uptake of ligand } \\
\text { marked positron }\end{array}$ & $\begin{array}{l}\text { Collection of neural } \\
\text { activity }\end{array}$ & $\begin{array}{l}\text { Magnetic fields produced } \\
\text { by brain's electrical activity }\end{array}$ \\
\hline & Measurement area & $\begin{array}{l}\text { Surface of the } \\
\text { cortex }\end{array}$ & $\begin{array}{l}\text { Whole brain } \\
\text { region }\end{array}$ & $\begin{array}{l}\text { Whole brain } \\
\text { region }\end{array}$ & $\begin{array}{l}\text { Surface of the cortex } \\
\text { unless using depth EEG }\end{array}$ & Surface of the cortex \\
\hline & Time resolution (s) & 1 & $2-3$ & $\geq 10$ & 0.01 & 0.01 \\
\hline & $\begin{array}{l}\text { Spatial resolution } \\
(\mathrm{mm})\end{array}$ & 20 & 5 & 10 & 20 & 10 \\
\hline & $\begin{array}{l}\text { Effect of } \\
\text { extra-cortical tissue }\end{array}$ & Some & Little & Little & Some & None \\
\hline \multirow[t]{3}{*}{$\begin{array}{l}\text { Measurement } \\
\text { setting }\end{array}$} & Invasiveness & No & No & $\begin{array}{l}\text { Intravenous } \\
\text { injection of } \\
\text { radioactive ligand }\end{array}$ & No & No \\
\hline & Body movement & Tolerable & No & No & No & No \\
\hline & Head restraint & No & Yes & Yes & No & Yes \\
\hline \multirow[t]{4}{*}{ Instrument } & Size & Small, movable & Large, fix & Large, fix & Large in research use & Large, fix \\
\hline & Transportability & Yes & No & No & Limited & No \\
\hline & Initial cost & $\begin{array}{l}300,000-400,000 \\
\text { USD }^{a}\end{array}$ & $\begin{array}{l}\text { Several million } \\
\text { USD }\end{array}$ & $\begin{array}{l}\text { Several million } \\
\text { USD }\end{array}$ & $100,000-300,000$ USD & Several million USD \\
\hline & $\begin{array}{l}\text { Measurement and } \\
\text { maintenance cost }\end{array}$ & Reasonable & Moderate & $\begin{array}{l}\text { Very expensive } \\
\text { (positron ligand) }\end{array}$ & Reasonable & Moderate \\
\hline
\end{tabular}

Bold shows advantages compared to other neuroimaging tools.

${ }^{a}$ ETG-4000 (Hitachi Medical Corporation).

distances and laser Doppler flowmetry were performed suggested that about $50 \%$ of fNIRS signals contributed to the fNIRS signal component in the deep layer, mostly measured in the cortex, during several cognitive tasks, including the VFT (38). A study of simultaneous measurement using fMRI, fNIRS, and lase Doppler flowmeter showed that the prefrontal fNIRS signals were significantly correlated with the blood oxygenation level-dependent (BOLD) signals in the gray matter rather than those in the soft tissue or the laser Doppler signals (39). Previous studies have suggested that the ratio of ANIRS signal changes in the cortex varies from 6 to $60 \%$, and the variation has been considered as being caused by differences in measuring instruments, estimation methods, and brain areas measured $(20,36-38,40-44)$. Several studies have provided filtering methods that allow raising the ratio of task-related hemoglobin changes in the cortex to in the extracortical tissues; however, these systems require additional probes and complex analytical methodologies because of different nearinfrared absorption and scattering coefficients in each tissue and anatomic characteristics throughout the light path in each brain area $(25,38,40,41)$. Therefore, fNIRS is a reliable tool for research based on the group-level and/or channel-cluster-level investigations, although its reliability at the individual and single-channel levels is not sufficient $(18,45-48)$. Few studies in clinical psychiatry have considered these filtering methods because of the limitations of measurement time and setting. Future studies will be needed to improve the signal-to-noise ratio for application over wide measurement areas without losing the advantage of fNIRS instruments.

\section{COMPARISON OF FNIRS HEMOGLOBIN CHANGES WITH BOLD SIGNALS IN fMRI}

The measurement of brain activity using the fMRI technique has progressed during the last two decades. The BOLD signal is thought to represent the differences in the magnetic properties of deoxygenated hemoglobin concentration under T2weighted measurement conditions when cerebral blood flow (CBF) increases and $\mathrm{HHb}$ decreases in small vessels (49). The theoretical model of BOLD compared with fNIRS signals was reviewed in detail elsewhere (18). Briefly, localized $\mathrm{O}_{2} \mathrm{Hb}$ decreases and $\mathrm{HHb}$ increases occur (i.e., initial dip) when neurons are activated in a specific region. Several seconds later, the blood flow system is triggered to request glucose to the region (i.e., hemodynamic response), which is followed by a CBF increase and peripheral vascular bed dilation, leading to $\mathrm{tHb}$ increase and $\mathrm{HHb}$ decrease in small vessels, and $\mathrm{O}_{2} \mathrm{Hb}$ increase in blood capillaries and vascular bed. As this neurovascular coupling that occurs in the activated area is thought to vary according to brain area and vessel diameter, and to be sensitive to persistent neural activity, the relationship between hemoglobin changes and BOLD/fNIRS signals has a complex variation pattern.

Other than the difference in spatio-temporal measurement characteristics between BOLD and FNIRS signals, the BOLD signal is thought to detect mainly changes in the magnetic properties of small vessels, whereas the fNIRS signal is thought to detect changes in near-infrared light absorption in blood capillaries (50). Therefore, several discrepancies may occur between BOLD and fNIRS signals. Previous fNIRS studies have yielded inconsistent 
results compared with other imaging tools. Simultaneous fNIRS and fMRI studies have shown that the BOLD signal in a specific region was associated with the $\mathrm{O}_{2} \mathrm{Hb}$ of fNIRS signal changes in the corresponding region $(25,29,39,51)$ or with $\mathrm{HHb}$ changes $(26-28,30,51)$. One of the explanations for these inconsistent correlation results is that most fNIRS studies have been conducted using block-designed tasks, whereas fMRI studies have mainly used an event-related design. In addition, the analysis of fMRI data by software such as Statistical Parametric Mapping (SPM) uses a hypothesis that fits a probable activation model, whereas most fNIRS studies have analyzed average signal intensity during the whole task period without any probable activation model. Differences in acquired signal handling may result in discrepancies regarding regions with significant brain activity. As $\mathrm{O}_{2} \mathrm{Hb}$ data generally exhibit larger changes compared with $\mathrm{HHb}$ during cognitive activity, most clinical fNIRS studies have mainly been analyzed using $\mathrm{O}_{2} \mathrm{Hb}$ data.

\section{ESTIMATION OF BRAIN AREA}

As more studies have focused on the spatial characteristics of brain activity using multi-channel fNIRS instruments, the need to clarify the estimated location of each probe in the cortex and each channel on the scalp has arisen. As reviewed by Tsuzuki et al. recently (52), several methodologies can estimate brain areas at each probe and channel, such as structural MRI measurement using fNIRS probe marks for each participant $(53,54)$, a probabilistic registration method using a 3D digitizer (55), and a probabilistic virtual registration method without any additional instrument (56). As the virtual registration method enables the estimation of brain areas based on standard brain images at each probe and channel by defining only probe setting based on the 10-20 system electrode locations, and because this method has similar accuracy compared with other estimation methodologies (56), most fNIRS studies have applied this method to estimate the measurement brain areas of channels. fNIRS software can also use the virtual registration method as a toolbox (http://www.jichi.ac.jp/brainlab/tools.html) (57). There are several standard stereotaxic coordinate systems such as the Montreal Neurological Institute (MNI) and the Talairach Daemon. The LONI Probabilistic Brain Atlas (LPBA40) (58) system has been often used in fNIRS studies based on probabilistic registration methods $(3,52,59,60)$.

\section{APPLICATION OF FNIRS IN SCHIZOPHRENIA RESEARCH}

Schizophrenia is a syndrome that is characterized by positive and negative symptoms and cognitive dysfunction with enduring social deficits. Moreover, it affects approximately $0.7 \%$ of the general population (2). The World Health Organization reported that the estimated burden of schizophrenia accounts for $2.3 \%$ of all diseases worldwide, and its disability-adjusted life year ranks ninth among all non-communicable diseases (61). However, effective treatments and objective indices for all symptoms and functions of schizophrenia have not been fully met.

Since the first fNIRS report of altered activation patterns in schizophrenia compared with healthy controls was published in 1994 (62), fNIRS research focusing on schizophrenia has been the most published topic in the field of psychiatry (9). We reviewed systematically research articles published up to April 1, 2013, by searching PubMed and Web of Science. As in previous systematic reviews $(9,18)$, we used "[(near infrared) OR (optical topography)] AND (schizo* OR psycho*) AND (brain OR cortex)" as a search term. Two hundred and sixty articles were extracted, among which 29 explored brain activity in patients with schizophrenia. Half of these articles (15 articles, including 4 studies of genetic variants) adopted a VFT as an activation cognitive battery during measurement.

\section{VERBAL FLUENCY TASK}

The VFT is a popular cognitive task that is used in neuropsychological tests and neuroimaging measurements to explore various cognitive functions during verbal recall, retrieval, working memory, attention, and inhibition (avoiding inappropriate words) (63, 64). During the task, participants are instructed to say as many words from a given paradigm as possible in a given time (usually $60 \mathrm{~s}$ ). This paradigm is roughly divided into semantic (category fluency task, CFT), such as fruits, or phonological (letter fluency task, LFT), such as words that begin with the letter "p." Neuropsychological studies have revealed that patients with schizophrenia have worse VFT performances compared with healthy controls (65). Although fMRI and fNIRS studies have shown that relatively global brain activity occurs during the VFT compared with a task that requires specific cognitive domains, such as the n-back working-memory task $(28,66)$ and the go/no-go task $(67)$, most participants (including patients with chronic schizophrenia) can perform the task $(10,11,19,63,64)$.

Eleven previous VFT studies are listed in Table 2. Watanabe and Kato firstly described that patients with schizophrenia had reduced $\mathrm{O}_{2} \mathrm{Hb}$ and $\mathrm{HHb}$ changes in the left PFC during the LFT compared with healthy controls (68). This study also demonstrated that patients who were medicated with atypical antipsychotics had better task performances and similar $\mathrm{O}_{2} \mathrm{Hb}$ changes compared with controls, suggesting that typical antipsychotics may impair task response and brain activity. However, that study did not explore whether impaired $\mathrm{O}_{2} \mathrm{Hb}$ changes were derived from impaired task response or functional impairment in the PFC, which may be ameliorated by atypical antipsychotics. Suto et al. firstly described the spatio-temporal activity patterns in the PFC and temporal cortex among patients with depression and schizophrenia and healthy controls using two 24-channel fNIRS machines (4). In that study, a modified task procedure was adopted in which three initial syllables changed in turn every $20 \mathrm{~s}$ during a $60 \mathrm{~s}$ task period, to help participants avoid silence and reduce differences in task performances among groups. Patients with schizophrenia had lower activity in the bilateral PFC and temporal cortex at the start of the task period compared with controls, whereas patients with depression had lower activity in the bilateral PFC and temporal cortex across the task period. These results were irrespective of task performance, and the task paradigm used in that study was used widely in further studies. In addition, this result was based on the Advanced Medical Technologies in Japan (10-12). Using a larger cohort, Takizawa et al. replicated the observation that patients with schizophrenia had slower and inappropriate activity after the task period compared with healthy controls (5). Furthermore, activities in the frontopolar prefrontal cortex (FPC) region were positively 
Table 2 | Previous fNIRS studies in schizophrenia using verbal fluency tasks.

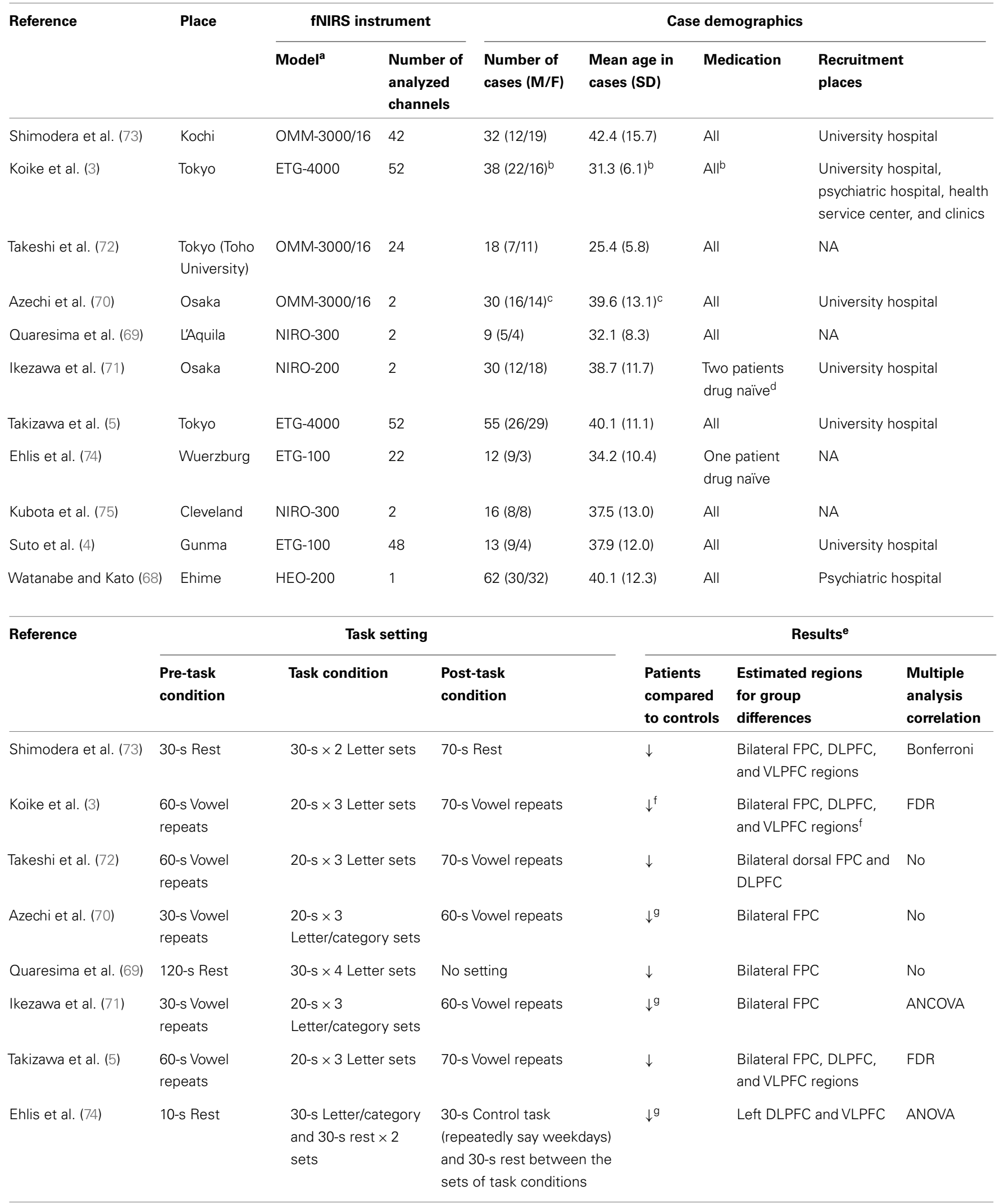


Table 2 | Continued

\begin{tabular}{|c|c|c|c|c|c|c|}
\hline \multirow[t]{2}{*}{ Reference } & \multicolumn{3}{|c|}{ Task setting } & \multicolumn{3}{|c|}{ Results ${ }^{e}$} \\
\hline & $\begin{array}{l}\text { Pre-task } \\
\text { condition }\end{array}$ & Task condition & $\begin{array}{l}\text { Post-task } \\
\text { condition }\end{array}$ & $\begin{array}{l}\text { Patients } \\
\text { compared } \\
\text { to controls }\end{array}$ & $\begin{array}{l}\text { Estimated regions } \\
\text { for group } \\
\text { differences }\end{array}$ & $\begin{array}{l}\text { Multiple } \\
\text { analysis } \\
\text { correlation }\end{array}$ \\
\hline Kubota et al. (75) & $\begin{array}{l}20-s \text { A vowel } \\
\text { repeats }\end{array}$ & $\begin{array}{l}\text { 15-s } \times 6 \\
\text { Letter/category sets }\end{array}$ & No setting & $\downarrow^{g}$ & Bilateral FPC & ANOVA \\
\hline Suto et al. (4) & $\begin{array}{l}\text { 30-s Vowel } \\
\text { repeats }\end{array}$ & $20-s \times 3$ Letter sets & 60-s Vowel repeats & - & - & ANOVA \\
\hline $\begin{array}{l}\text { Watanabe and Kato } \\
\text { (68) }\end{array}$ & $\begin{array}{l}\text { 15-s No detailed } \\
\text { description }\end{array}$ & 60 -s One letter set & $\begin{array}{l}\text { 15-s No detailed } \\
\text { description }\end{array}$ & $\downarrow$ & Left FPC & ANOVA \\
\hline
\end{tabular}

\begin{tabular}{|c|c|c|c|}
\hline \multirow[t]{2}{*}{ Reference } & \multicolumn{3}{|c|}{ Correlational analysis between clinical variables and fNIRS signals } \\
\hline & GAF & Other clinical variables & Medication \\
\hline Shimodera et al. (73) & NA & n.s. & NA \\
\hline Koike et al. (3) & $\begin{array}{l}\text { Positive association in the } \\
\text { FPC region in the chronic } \\
\text { schizophrenia group }\end{array}$ & $\begin{array}{l}\text { Positive association with PANSS positive or negative scores in } \\
\text { the FEP group }\end{array}$ & $\begin{array}{l}\text { n.s. (including no } \\
\text { difference between } \\
\text { UHR individuals with } \\
\text { and without medication) }\end{array}$ \\
\hline Takeshi et al. (72) & $\begin{array}{l}\text { n.s., But positive } \\
\text { association in the FPC } \\
\text { during an idea fluency task }\end{array}$ & NA & NA \\
\hline Azechi et al. (70) & NA & n.s. & n.s. \\
\hline Quaresima et al. (69) & NA & NA & NA \\
\hline Ikezawa et al. (71) & NA & n.s. & n.s. \\
\hline Takizawa et al. (5) & $\begin{array}{l}\text { Positive association in the } \\
\text { FPC and right DLPFC } \\
\text { regions }\end{array}$ & $\begin{array}{l}\text { Negative correlation with age at measurement, positive } \\
\text { correlation with PANSS positive score, and negative correlation } \\
\text { with PANSS general psychopathology score in schizophrenia }\end{array}$ & n.s. \\
\hline Ehlis et al. (74) & NA & NA & n.s. \\
\hline Kubota et al. (75) & NA & NA & NA \\
\hline Suto et al. (4) & NA & NA & NA \\
\hline Watanabe and Kato (68) & NA & n.s. & n.s. \\
\hline
\end{tabular}

Excluded previous gene association studies.

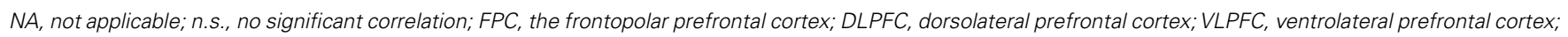

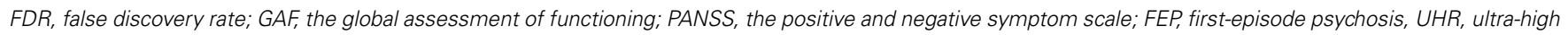
risk.

a OMM-3000/16, Shimadzu Corporation; ETG-4000 and ETG-100, Hitachi Medical Corporation; NIRO-300 and NIRO-200, Hamamatsu Photonics Corporation; HEO-200, Omron Healthcare Corporation.

${ }^{b}$ Exhibit case in the chronic schizophrenia group. Sixteen UHR and 2 FEP individuals were antipsychotics naïve and 8 UHR and 1 FEP individuals were drug naïve.

${ }^{c}$ As Azechi et al. (70) used the same sample from Ikezawa et al. (71) as the First group, we describe for the Second group.

${ }^{d}$ By Azechi et al. (70).

${ }^{e}$ Results from brain activity during the whole of the task period.

${ }^{t}$ Results in the chronic schizophrenia group.

${ }^{g}$ Results during the letter fluency tasks.

associated with global assessment of functioning scores in schizophrenia. Quaresuma et al. replicated the finding of reduced brain activity in schizophrenia during the LFT, whereas no significant change was observed during a visual spatial working memory task (69). Ikezawa et al. and Azechi et al. showed the efficacy of the LFT task in fNIRS $(70,71)$. Ikezawa et al. measured hemoglobin 
changes in the PFC using a two-channel fNIRS instrument during the LFT, CFT, Tower of Hanoi $(\mathrm{TOH})$, the Sternberg task, and the Stroop task, and showed that brain activities during the LFT and TOH were significantly different between patients with schizophrenia and healthy controls (71). Azechi et al. explored this further using discrimination analysis and showed that $88.3 \%$ of participants correctly discriminated between patients and controls based on task performance on the TOH, LFT, and CFT, and on fNIRS signals during the VFT (70). This result confirmed that $75 \%$ of independent participants were able to discriminate correctly using the same procedure. Koike et al. explored the signal differences among different clinical stages of schizophrenia (ultrahigh risk, first-episode psychosis, and chronic schizophrenia) and showed that the activities in the FPC, ventrolateral PFC (VLPFC), and temporal cortex were lower in patients than they were in controls, whereas the activities in the dorsolateral PFC (DLPFC) decreased with advancing clinical stage (3). Those authors also replicated the finding that the activity in the FPC region was positively associated with global assessment of functioning scores in chronic schizophrenia, implying that it may be a candidate biomarker for the assessment of psychological condition in schizophrenia $(3,5)$. Takeshi et al. measured brain activity during the idea fluency task, which is thought to require more executive function, and showed that patients with schizophrenia had decreased activity in the ventral area of the PFC (72). Furthermore, these signal changes were positively associated with the global assessment of functioning scores, whereas $\mathrm{O}_{2} \mathrm{Hb}$ changes during the LFT were not. Shimodera et al. replicated the characteristic waveforms in schizophrenia, such as smaller initial activity at the start of the task period, reduced activity during the task period, and inappropriate activity after the task period, and used a numerical calculation (73).

The CFT has also been used in fNIRS studies, which often compare this task to the LFT. Kubota et al. used a two-channel fNIRS instrument to show for the first time that healthy controls had larger activity in the PFC during the LFT than in the CFT under similar task performances, whereas patients with schizophrenia had smaller activity during the LFT than during the CFT (75). Patients with schizophrenia had smaller activity than did healthy controls under similar task performances between the groups. This result is consistent with those of other studies $(70,71)$. Ehlis et al. used a multi-channel fNIRS instrument that covered the left frontotemporal region and found that healthy controls had larger and spatially wider activities during the LFT compared with the CFT (74), which was then replicated by measuring wider areas of the bilateral prefrontal/temporal cortices (76). Ehlis et al. also replicated the finding that patients with schizophrenia had significantly reduced activities compared with healthy controls during LFT, but not during the CFT.

\section{APPLICATION OF FNIRS AS A SUPPLEMENTARY DIAGNOSIS TOOL FOR PSYCHIATRIC DISORDERS}

As described above, previous studies using a block-design LFT have indicated that patients with schizophrenia have not only reduced activity, but also inappropriate activity timing, especially at the start of the task period and post-task period, compared with healthy controls $(4,5)$. Subsequently, the Joint Project for Psychiatric Application of Near-Infrared Spectroscopy (JPSYNIRS) Group has applied to these results and improved in the applicable way for clinical settings. The integral value (the size of the fNIRS signal area during the task period) and centroid value (the centroid time of the fNIRS signal area throughout the task) were determined by using averaged brain signals estimated in the frontopolar cortex. This group showed preliminarily that $69 \%$ of patients with MDD and $69 \%$ of patients with schizophrenia, and $69 \%$ MDD patients and $81 \%$ BP patients were correctly differentiated under an algorithm using these two values $(10,11)$. A part of these results was approved as one of the Advanced Medical Technologies as an aid for the differential diagnosis of depressive symptoms in 2009, which was the first such approval in the field of psychiatry in Japan $(10,11)$. Several criticisms have arisen regarding the limited replication in various clinical settings and the lack of consensus for application to mental health $(77,78)$. However, paper published recently on JPSY-NIRS replicated previous results (12). Using this algorithm, fNIRS can differentiate patients with depressive symptoms between major depressive disorder and psychotic disorders (bipolar disorder and schizophrenia), with a high classification rate (74.6 and $85.5 \%$, respectively).

\section{OTHER COGNITIVE TASKS AND MEASUREMENT SETTINGS}

Three studies have explored the differences in brain activity during a random generation task (RNG) between patients with schizophrenia and healthy controls. Sinba et al. used a two-channel fNIRS instrument to describe for the first time that patients with schizophrenia had reduced brain activity in the PFC and worse task performances during the RNG compared with healthy controls, which represented different features during ruler-catching and sequential finger-to-thumb tasks (79). As healthy controls with better RNG task performances had greater brain activity, it remained unclear whether low brain activity was derived from worse task execution and/or functional impairment in schizophrenia. Hoshi et al. used time-resolved spectroscopy and two-channel fNIRS instruments to show that patients with schizophrenia, particularly those with a longer duration of illness, had reduced hemoglobin concentration during the resting state, and that this may cause altered activity during the RNG task (80). Koike et al. used a multi-channel fNIRS instrument to show that patients with schizophrenia had significantly reduced activity in the bilateral DLPFC and VLPFC regions, and that the activity in the right DLPFC region was associated with an earlier age at onset (81).

Okada et al. firstly showed the presence of altered brain activity in schizophrenia using a two-channel fNIRS instrument (62). Patients with schizophrenia had an aberrant task-related response pattern during a mirror drawing task, which was thought to be derived from a disrupted interhemispheric integration. Fallgatter et al. also showed the presence of altered frontal lateralization in schizophrenia during a continuous performance task using a twochannel fNIRS instrument (82). Folley et al. explored brain activity in patients with schizophrenia, individuals with schizotypal personality, and healthy controls during a divergent-thinking task using a two-channel fNIRS instrument, and showed that individuals with schizotypal personality had enhanced divergent-thinking ability and greater brain activity in the right PFC compared with patients with schizophrenia and healthy controls (83). Lee et al. 
showed alternations in brain activity using fMRI and 24-channel fNIRS (not simultaneously) during the same event-related spatial working-memory task: patients with schizophrenia recruited the bilateral PFC, whereas healthy controls recruited only the right PFC (28). Zhu et al. used a 48-channel fNIRS instrument to show that patients with first-episode schizophrenia had reduced brain activity over the PFC during the Tower of London task (84). Nishimura et al. used a 52-channel fNIRS instrument during a go-no-go task to show that healthy controls had a significant decrease in activity in the DLPFC during the no-go condition, whereas patients with schizophrenia exhibited no changes (67). Furthermore, the high excitement score observed in patients with schizophrenia was associated with brain activity in the FPC and right DLPFC. Taniguchi et al. used a 24-channel fNIRS instrument to show that patients with schizophrenia had reduced brain activity in the PFC compared with healthy controls during a kana Stroop task, with similar task performances, whereas both patients and controls showed lack of activity during a kanji Stroop task, with significantly worse performance observed in the schizophrenia group (85).

Other than cognitive tasks, Fujita et al. explored hemoglobin changes through an electroconvulsive therapy using a two-channel fNIRS instrument, and showed that patients with schizophrenia had asymmetric hemoglobin changes in the PFC compared with patients with depression (86).

\section{GENETIC VARIATION}

Although schizophrenia is a syndrome, has been considered as a consolidation of several pathophysiological features, and has high genetic heritability, no crucial genetic risk factor has been found $(87,88)$. The results of genome-wide association studies that used a large sample size have suggested that schizophrenia risk genes are unable to be determined by specific gene variants but are thought to consist of common variants; furthermore, these risk genes had a substantial influence on environmental effects that occurred before the onset of schizophrenia. To clarify the impact of specific genes related to schizophrenia on the brain, imaging/genetics studies were performed to explore the relationship between brain structure and activity and genetic variants.

Five studies have explored the relationship between genetic variants and brain activity using fNIRS instruments. Takizawa et al. firstly reported that the val108/158met polymorphism of the catechol-O-methyltransferase (COMT) gene affected brain activity in the PFC only in schizophrenia patients (and not in healthy controls) (89). Schizophrenia patients with the Met variant (Val/Met and Met/Met) had significantly greater activation in the bilateral FPC and DLPFC during the LFT than did Val/Val carriers, implying that the inverted $U$ curve shift of dopamine availability in schizophrenia might have an effect on the brain activity in the PFC (89). Regarding the Gln/Pro polymorphism of the sigma-1 receptor gene, Takizawa et al. reported that patients with the Gln/Gln genotype had significantly greater brain activity in the FPC and left DLPFC during the LFT than did Pro allele carriers; however, no significant differences were observed in healthy controls (90). However, Ohi et al. later used a two-channel fNIRS machine and a larger sample set to show that this genotype effect occurred in both the schizophrenia and control groups (91). Ohi et al. also reported that individuals with a longer cytosine/adenine/guanine (CAG) repeat in the spinocerebellar ataxia type 17 gene had reduced activity in the bilateral PFC during the TOH task in both the schizophrenia and control groups (92). Regarding the rs41279104 polymorphism of the nitric oxide synthase-I gene, Reif et al. showed that patients who were A allele carriers had significantly reduced activity in the right PFC during a VFT compared with those who had the GG genotype (93).

As recent methodological progress in gene analysis allows the exploration of whole genetic alterations between cases and controls using more than 10,000 samples, imaging/genetics studies should be performed using methods that enable the analysis of numerical data sets, such as bioinformatics and machine learning methods (94). Conversely, the investigation of the relationship between brain activity and relevant target genes (e.g., DLPFC function under dopamine regulation and COMT variants) may provide another imaging/genetics study strategy. The analysis of altered gene function in the brain among psychiatric illnesses may clarify the pathophysiology of specific psychiatric disorders and identify new treatment options.

\section{EFFECT OF MEDICATION ON BRAIN ACTIVITY}

As previous clinical fNIRS studies have mostly explored patients in the chronic stage and receiving medication, the effect of medication on brain function was a limitation of these studies. Although an inconsistent effect of medication on fNIRS signal has been reported $(68,70,71,79)$, most previous fNIRS studies have reported an absence of association between brain activity and medication dose $(3,5,12,74,81,84-86)$ or different brain activity between individuals with ultra-high risk for psychosis with and without medication (3) (Table 1). However, all of those studies were cross-sectional, and a previous randomized and controlled trial showed that the administration of mirtazapine increased brain activity compared with trazodone and placebo in healthy volunteers (95). Controlled trials and/or longitudinal investigation to elucidate specific drug effects will be needed.

\section{LIMITATIONS OF PREVIOUS STUDIES AND FURTHER DIRECTIONS}

The previous fNIRS studies of schizophrenia had several limitations; therefore, we propose further directions for future investigation (Table 3). First, as most previous studies have performed cross-sectional measurements in chronic and stable patients receiving medication, symptomatic, and functional changes were not fully explored. As fNIRS is able to perform measurements relatively easily in unstable patients, such as those with acute or recurrent conditions, longitudinal studies aimed at investigating changes in clinical symptoms and social function will be needed (3, 96). Although previous studies have revealed a negligible medication effect on fNIRS signals, investigations of drug-naïve patients or of those receiving controlling treatment (e.g., specific drugs, electroconvulsive therapy, and neurofeedback) will be needed to allow further clinical applications of fNIRS $(60,86,97)$. The use of the easy portability of fNIRS machines may allow measurements in earlier clinical stages in cohort settings, such as adolescents with psychotic-like experiences, which may reveal the alterations in brain development in the PFC (98). 
Table 3 | Limitation of previous fNIRS studies and further implication.

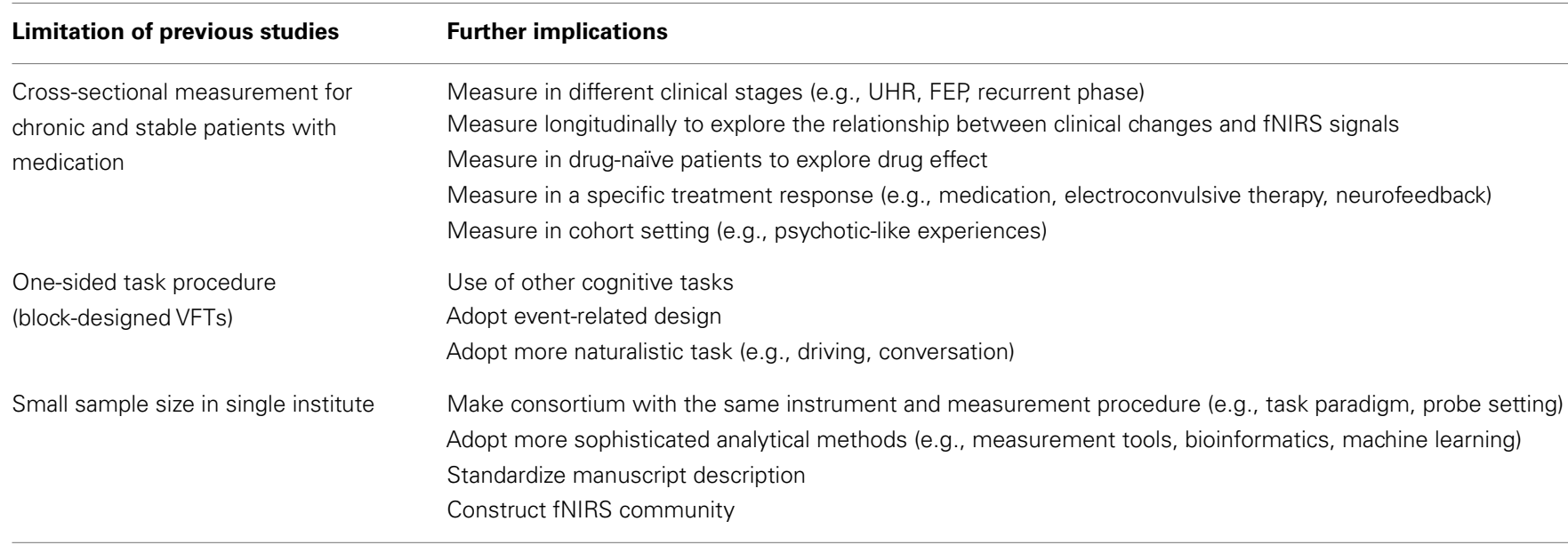

UHR, ultra-high risk; FEP, first-episode psychosis.

Second, half of the previous studies of schizophrenia adopted block-design VFTs for cognitive activation. Although one of the major disadvantages of fNIRS is the inability to measure brain activity in deep brain tissues, and the block-design VFT is appropriate for elucidating brain activity over the PFC, other cognitive tasks, and event-related design will be helpful to explore brain pathology in schizophrenia and to compare signal differences between fNIRS and other neuroimaging tools, such as fMRI and PET. Conversely, the exploration of brain activity in a more naturalistic position and during natural activities, such as driving and conversation, is suitable for future investigations using the advantages of fNIRS $(99,100)$.

Third, as fNIRS allows easy and repetitive measurements, a study including a large number of samples has been conducted (12). To analyze such a large data set, the same measurement procedure regarding task paradigm and probe setting and more sophisticated analytical methods, such as measurement tools (e.g., NIRS-SPM) (101), bioinformatics methods, and machine learning (94), will be needed. Standardized manuscript description and a database system will be needed for further comparisons and meta-analyses (102). The construction of an fNIRS community is expected to provide this type of background in NIRS research (18).

\section{CONCLUSION}

Functional near-infrared spectroscopy has been progressing rapidly in the field of psychiatry, as it provides several advantages, such as small size, portability, silent functioning, and the achievement of easy and non-invasive measurements. A part of these results was approved in 2009 as one of the Advanced Medical Technologies as an aid for the differential diagnosis of depressive symptoms (10-12), which was the first such approval in the field of psychiatry in Japan. Future investigations aimed at exploring fNIRS differences in various clinical stages, longitudinal changes, drug effects, and variations during different task paradigms will be needed to develop more accurate biomarkers that can be used to aid differential diagnosis, the comprehension of the present condition, the prediction of outcome, and the decision regarding treatment options in schizophrenia.
Future fNIRS research environments will require standardized measurement procedures, probe settings, analytical methods and tools, manuscript description, and database systems in a n fNIRS community.

\section{ACKNOWLEDGMENTS}

I would like to thank Mika Yamagishi and Hanako Sakurada for substantial support in article search. This study was supported by grants from the Ministry of Health, Labor, and Welfare (Health and Labor Science Research Grant for Comprehensive Research on Disability Health and Welfare H22-seishin-ippan-015 to Kiyoto Kasai) and from the JSPS/MEXT (No. 25870143 to Shinsuke Koike, and Grant-in-Aid for Scientific Research on Innovative Areas [Comprehensive Brain Science Network and Adolescent Mind and Self-Regulation (23118001 and 23118004) to Kiyoto Kasai], and National Bioscience Database Center (NBDC) of Japan Science and Technology Agency (JST) to Kiyoto Kasai. A portion of this study was also the result of a project entitled "Development of biomarker candidates for social behavior" carried out under the Strategic Research Program for Brain Sciences by the MEXT.

\section{REFERENCES}

1. Anonymous. A decade for psychiatric disorders. Nature (2010) 463:9. doi:10. 1038/463009a

2. Insel TR. Rethinking schizophrenia. Nature (2010) 468:187-93. doi:10.1038/ nature09552

3. Koike S, Takizawa R, Nishimura Y, Takano Y, Takayanagi Y, Kinou M, et al. Different hemodynamic response patterns in the prefrontal cortical sub-regions according to the clinical stages of psychosis. Schizophr Res (2011) 132:54-61. doi:10.1016/j.schres.2011.07.014

4. Suto T, Fukuda M, Ito M, Uehara T, Mikuni M. Multichannel near-infrared spectroscopy in depression and schizophrenia: cognitive brain activation study. Biol Psychiatry (2004) 55:501-11. doi:10.1016/j.biopsych.2003.09.008

5. Takizawa R, Kasai K, Kawakubo Y, Marumo K, Kawasaki S, Yamasue H, et al. Reduced frontopolar activation during verbal fluency task in schizophrenia: a multi-channel near-infrared spectroscopy study. Schizophr Res (2008) 99:250-62. doi:10.1016/j.schres.2007.10.025

6. Jobsis FF. Noninvasive, infrared monitoring of cerebral and myocardial oxygen sufficiency and circulatory parameters. Science (1977) 198:1264-7. doi:10.1126/science.929199

7. Hoshi Y, Tamura M. Dynamic multichannel near-infrared optical imaging of human brain activity. J Appl Physiol (1993) 75:1842-6. 
8. Kato T, Kamei A, Takashima S, Ozaki T. Human visual cortical function during photic stimulation monitoring by means of near-infrared spectroscopy. J Cereb Blood Flow Metab (1993) 13:516-20. doi:10.1038/jcbfm.1993.66

9. Ehlis AC, Schneider S, Dresler T, Fallgatter AJ. Application of functional near-infrared spectroscopy in psychiatry. Neuroimage (2013). doi:10.1016/j. neuroimage.2013.03.067

10. Fukuda M. Near-infrared spectroscopy in psychiatry. Brain Nerve (2012) 64:175-83.

11. Fukuda M, Mikuni M. Clinical application of near-infrared spectroscopy (NIRS) in psychiatry: the advanced medical technology for differential diagnosis of depressive state. Seishin Shinkeigaku Zasshi (2012) 114:801-6.

12. Takizawa R, Fukuda M, Kawasaki S, Kasai K, Mimura M, Pu S, et al. Neuroimaging-aided differential diagnosis of the depressive state. Neuroimage (2013). doi:10.1016/j.neuroimage.2013.05.126

13. Kameyama M, Fukuda M, Yamagishi Y, Sato T, Uehara T, Ito M, et al. Frontal lobe function in bipolar disorder: a multichannel near-infrared spectroscopy study. Neuroimage (2006) 29:172-84. doi:10.1016/j.neuroimage.2005.07.025

14. Noda T, Yoshida S, Matsuda T, Okamoto N, Sakamoto K, Koseki S, et al. Frontal and right temporal activations correlate negatively with depression severity during verbal fluency task: a multi-channel near-infrared spectroscopy study. J Psychiatr Res (2012) 46:905-12. doi:10.1016/j.jpsychires.2012.04.001

15. Ohta H, Yamagata B, Tomioka H, Takahashi T, Yano M, Nakagome K, et al. Hypofrontality in panic disorder and major depressive disorder assessed by multi-channel near-infrared spectroscopy. Depress Anxiety (2008) 25:1053-9. doi:10.1002/da.20463

16. Pu S, Matsumura H, Yamada T, Ikezawa S, Mitani H, Adachi A, et al. Reduced frontopolar activation during verbal fluency task associated with poor social functioning in late-onset major depression: multi-channel near-infrared spectroscopy study. Psychiatry Clin Neurosci (2008) 62:728-37. doi:10.1111/j.14401819.2008.01882.x

17. Pu S, Nakagome K, Yamada T, Yokoyama K, Matsumura H, Mitani H, et al. The relationship between the prefrontal activation during a verbal fluency task and stress-coping style in major depressive disorder: a near-infrared spectroscopy study. J Psychiatr Res (2012) 46:1427-34. doi:10.1016/j.jpsychires. 2012.08.001

18. Ferrari M, Quaresima V. A brief review on the history of human functional near-infrared spectroscopy (fNIRS) development and fields of application. Neuroimage (2012) 63:921-35. doi:10.1016/j.neuroimage.2012.03.049

19. Dieler AC, Tupak SV, Fallgatter AJ. Functional near-infrared spectroscopy for the assessment of speech related tasks. Brain Lang (2012) 121:90-109. doi:10.1016/j.bandl.2011.03.005

20. Scholkmann F, Kleiser S, Metz AJ, Zimmermann R, Mata Pavia J, Wolf U, et al. A review on continuous wave functional near-infrared spectroscopy and imaging instrumentation and methodology. Neuroimage (2013). doi:10.1016/ j.neuroimage.2013.05.004

21. Minagawa-Kawai Y, Mori K, Hebden JC, Dupoux E. Optical imaging of infants' neurocognitive development: recent advances and perspectives. Dev Neurobiol (2008) 68:712-28. doi:10.1002/dneu.20618

22. Homae F, Watanabe H, Otobe T, Nakano T, Go T, Konishi Y, et al. Development of global cortical networks in early infancy. J Neurosci (2010) 30:4877-82. doi:10.1523/JNEUROSCI.5618-09.2010

23. Ehlis AC, Ringel TM, Plichta MM, Richter MM, Herrmann MJ, Fallgatter AJ. Cortical correlates of auditory sensory gating: a simultaneous near-infrared spectroscopy event-related potential study. Neuroscience (2009) 159:1032-43. doi:10.1016/j.neuroscience.2009.01.015

24. Herrmann MJ, Huter T, Plichta MM, Ehlis AC, Alpers GW, Muhlberger A, et al. Enhancement of activity of the primary visual cortex during processing of emotional stimuli as measured with event-related functional near-infrared spectroscopy and event-related potentials. Hum Brain Mapp (2008) 29:28-35. doi:10.1002/hbm.20368

25. Heinzel S, Haeussinger FB, Hahn T, Ehlis AC, Plichta MM, Fallgatter AJ. Variability of (functional) hemodynamics as measured with simultaneous fNIRS and fMRI during intertemporal choice. Neuroimage (2013) 71:125-34. doi:10.1016/j.neuroimage.2012.12.074

26. Huppert TJ, Hoge RD, Diamond SG, Franceschini MA, Boas DA. A temporal comparison of BOLD, ASL, and NIRS hemodynamic responses to motor stimuli in adult humans. Neuroimage (2006) 29:368-82. doi:10.1016/j.neuroimage. 2005.08.065
27. Kleinschmidt A, Obrig H, Requardt M, Merboldt KD, Dirnagl U, Villringer A, et al. Simultaneous recording of cerebral blood oxygenation changes during human brain activation by magnetic resonance imaging and near-infrared spectroscopy. J Cereb Blood Flow Metab (1996) 16:817-26. doi:10.1097/ 00004647-199609000-00006

28. Lee J, Folley BS, Gore J, Park S. Origins of spatial working memory deficits in schizophrenia: an event-related FMRI and near-infrared spectroscopy study. PLoS One (2008) 3:e1760. doi:10.1371/journal.pone.0001760

29. Strangman G, Culver JP, Thompson JH, Boas DA. A quantitative comparison of simultaneous BOLD fMRI and NIRS recordings during functional brain activation. Neuroimage (2002) 17:719-31. doi:10.1006/nimg.2002.1227

30. Toronov V, Walker S, Gupta R, Choi JH, Gratton E, Hueber D, et al. The roles of changes in deoxyhemoglobin concentration and regional cerebral blood volume in the fMRI BOLD signal. Neuroimage (2003) 19:1521-31. doi:10.1016/S1053-8119(03)00152-6

31. Hock C, Villringer K, Muller-Spahn F, Wenzel R, Heekeren H, Schuh-Hofer $\mathrm{S}$, et al. Decrease in parietal cerebral hemoglobin oxygenation during performance of a verbal fluency task in patients with Alzheimer's disease monitored by means of near-infrared spectroscopy (NIRS) - correlation with simultaneous rCBF-PET measurements. Brain Res (1997) 755:293-303. doi:10.1016/ S0006-8993(97)00122-4

32. Hoshi Y, Onoe H, Watanabe Y, Andersson J, Bergstrom M, Lilja A, et al. Non-synchronous behavior of neuronal activity, oxidative metabolism and blood supply during mental tasks in man. Neurosci Lett (1994) 172:129-33. doi:10.1016/0304-3940(94)90679-3

33. Ohmae E, Ouchi Y, Oda M, Suzuki T, Nobesawa S, Kanno T, et al. Cerebral hemodynamics evaluation by near-infrared time-resolved spectroscopy: correlation with simultaneous positron emission tomography measurements. Neuroimage (2006) 29:697-705. doi:10.1016/j.neuroimage.2005.08.008

34. Sander TH, Liebert A, Burghoff M, Wabnitz H, Macdonald R, Trahms L. Crosscorrelation analysis of the correspondence between magnetoencephalographic and near-infrared cortical signals. Methods Inf Med (2007) 46(2):164-8.

35. Seki Y, Miyashita T, Kandori A, Maki A, Koizumi H. Simultaneous measurement of neuronal activity and cortical hemodynamics by unshielded magnetoencephalography and near-infrared spectroscopy. J Biomed Opt (2012) 17(10):107001. doi:10.1117/1.JBO.17.10.107001

36. Takahashi T, Takikawa Y, Kawagoe R, Shibuya S, Iwano T, Kitazawa S. Influence of skin blood flow on near-infrared spectroscopy signals measured on the forehead during a verbal fluency task. Neuroimage (2011) 57:991-1002. doi:10.1016/j.neuroimage.2011.05.012

37. Kirilina E, Jelzow A, Heine A, Niessing M, Wabnitz H, Bruhl R, et al. The physiological origin of task-evoked systemic artefacts in functional near infrared spectroscopy. Neuroimage (2012) 61:70-81. doi:10.1016/j.neuroimage.2012.02.074

38. Funane T, Atsumori H, Katura T, Obata AN, Sato H, Tanikawa Y, et al. Quantitative evaluation of deep and shallow tissue layers' contribution to fNIRS signal using multi-distance optodes and independent component analysis. Neuroimage (2013). doi:10.1016/j.neuroimage.2013.02.026

39. Sato H, Yahata N, Funane T, Takizawa R, Katura T, Atsumori H, et al. A NIRSfMRI investigation of prefrontal cortex activity during a working memory task. Neuroimage (2013) 83:158-73. doi:10.1016/j.neuroimage.2013.06.043

40. Gagnon L, Yücel MA, Boas DA, Cooper RJ. Further improvement in reducing superficial contamination in NIRS using double short separation measurements. Neuroimage (2013). doi:10.1016/j.neuroimage.2013.01.073

41. Gagnon L, Cooper RJ, Yucel MA, Perdue KL, Greve DN, Boas DA. Short separation channel location impacts the performance of short channel regression in NIRS. Neuroimage (2011) 59:2518-28. doi:10.1016/j.neuroimage.2011.08.095

42. Gagnon L, Yucel MA, Dehaes M, Cooper RJ, Perdue KL, Selb J, et al. Quantification of the cortical contribution to the NIRS signal over the motor cortex using concurrent NIRS-fMRI measurements. Neuroimage (2012) 59(4):3933-40. doi:10.1016/j.neuroimage.2011.10.054

43. Haeussinger FB, Heinzel S, Hahn T, Schecklmann M, Ehlis AC, Fallgatter AJ. Simulation of near-infrared light absorption considering individual head and prefrontal cortex anatomy: implications for optical neuroimaging. PLoS One (2011) 6:e26377. doi:10.1371/journal.pone.0026377

44. Kohri S, Hoshi Y, Tamura M, Kato C, Kuge Y, Tamaki N. Quantitative evaluation of the relative contribution ratio of cerebral tissue to near-infrared signals in the adult human head: a preliminary study. Physiol Meas (2002) 23:301-12. doi:10.1088/0967-3334/23/2/306 
45. Kakimoto Y, Nishimura Y, Hara N, Okada M, Tanii H, Okazaki Y. Intrasubject reproducibility of prefrontal cortex activities during a verbal fluency task over two repeated sessions using multi-channel near-infrared spectroscopy. Psychiatry Clin Neurosci (2009) 63:491-9. doi:10.1111/j.1440-1819.2009.01988.x

46. Kono T, Matsuo K, Tsunashima K, Kasai K, Takizawa R, Rogers MA, et al. Multiple-time replicability of near-infrared spectroscopy recording during prefrontal activation task in healthy men. Neurosci Res (2007) 57:504-12. doi:10.1016/j.neures.2006.12.007

47. Plichta MM, Herrmann MJ, Baehne CG, Ehlis AC, Richter MM, Pauli P, et al. Event-related functional near-infrared spectroscopy (fNIRS): are the measurements reliable? Neuroimage (2006) 31:116-24. doi:10.1016/j.neuroimage. 2005. 12.008

48. Schecklmann M, Ehlis AC, Plichta MM, Fallgatter AJ. Functional near-infrared spectroscopy: a long-term reliable tool for measuring brain activity during verbal fluency. Neuroimage (2008) 43:147-55. doi:10.1016/j.neuroimage.2008.06. 032

49. Ogawa S, Lee TM, Kay AR, Tank DW. Brain magnetic resonance imaging with contrast dependent on blood oxygenation. Proc Natl Acad Sci U S A (1990) 87:9868-72. doi:10.1073/pnas.87.24.9868

50. Yamamoto T, Kato T. Paradoxical correlation between signal in functional magnetic resonance imaging and deoxygenated haemoglobin content in capillaries: a new theoretical explanation. Phys Med Biol (2002) 47:1121-41. doi:10.1088/0031-9155/47/7/309

51. Cui X, Bray S, Bryant DM, Glover GH, Reiss AL. A quantitative comparison of NIRS and fMRI across multiple cognitive tasks. Neuroimage (2011) 54:2808-21. doi:10.1016/j.neuroimage.2010.10.069

52. Tsuzuki D, Dan I. Spatial registration for functional near-infrared spectroscopy: from channel position on the scalp to cortical location in individual and group analyses. Neuroimage (2013). doi:10.1016/j.neuroimage.2013.07.025

53. Okamoto M, Dan H, Sakamoto K, Takeo K, Shimizu K, Kohno S, et al. Threedimensional probabilistic anatomical cranio-cerebral correlation via the international 10-20 system oriented for transcranial functional brain mapping. Neuroimage (2004) 21:99-111. doi:10.1016/j.neuroimage.2003.08.026

54. Schroeter ML, Zysset S, Kupka T, Kruggel F, Yves von Cramon D. Nearinfrared spectroscopy can detect brain activity during a color-word matching Stroop task in an event-related design. Hum Brain Mapp (2002) 17:61-71. doi:10.1002/hbm.10052

55. Singh AK, Okamoto M, Dan H, Jurcak V, Dan I. Spatial registration of multichannel multi-subject fNIRS data to MNI space without MRI. Neuroimage (2005) 27:842-51. doi:10.1016/j.neuroimage.2005.05.019

56. Tsuzuki D, Jurcak V, Singh AK, Okamoto M, Watanabe E, Dan I. Virtual spatial registration of stand-alone fNIRS data to MNI space. Neuroimage (2007) 34:1506-18. doi:10.1016/j.neuroimage.2006.10.043

57. Katura T, Sato H, Fuchino Y, Yoshida T, Atsumori H, Kiguchi M, et al. Extracting task-related activation components from optical topography measurement using independent components analysis. J Biomed Opt (2008) 13:054008. doi:10.1117/1.2981829

58. Shattuck DW, Mirza M, Adisetiyo V, Hojatkashani C, Salamon G, Narr KL, et al. Construction of a 3D probabilistic atlas of human cortical structures. Neuroimage (2008) 39:1064-80. doi:10.1016/j.neuroimage.2007.09.031

59. Heinzel S, Metzger FG, Ehlis AC, Korell R, Alboji A, Haeussinger FB, et al. Aging-related cortical reorganization of verbal fluency processing: a functional near-infrared spectroscopy study. Neurobiol Aging (2013) 34:439-50. doi:10.1016/j.neurobiolaging.2012.05.021

60. Monden Y, Dan H, Nagashima M, Dan I, Kyutoku Y, Okamoto M, et al. Clinically-oriented monitoring of acute effects of methylphenidate on cerebral hemodynamics in ADHD children using fNIRS. Clin Neurophysiol (2012) 123:1147-57. doi:10.1016/j.clinph.2011.10.006

61. World Health Organization (WHO). Global Burden of Disease. New York: World Health Organization (2004).

62. Okada F, Tokumitsu Y, Hoshi Y, Tamura M. Impaired interhemispheric integration in brain oxygenation and hemodynamics in schizophrenia. Eur Arch Psychiatry Clin Neurosci (1994) 244:17-25. doi:10.1007/BF02279807

63. Cabeza R, Nyberg L. Imaging cognition II: an empirical review of 275 PET and fMRI studies. J Cogn Neurosci (2000) 12:1-47. doi:10.1162/ 08989290051137585

64. Curtis VA, Bullmore ET, Brammer MJ, Wright IC, Williams SC, Morris RG, et al. Attenuated frontal activation during a verbal fluency task in patients with schizophrenia. Am J Psychiatry (1998) 155:1056-63.
65. Green MF, Nuechterlein KH, Gold JM, Barch DM, Cohen J, Essock S, et al. Approaching a consensus cognitive battery for clinical trials in schizophrenia: the NIMH-MATRICS conference to select cognitive domains and test criteria. Biol Psychiatry (2004) 56:301-7. doi:10.1016/j.biopsych.2004.06.023

66. Koike S, Takizawa R, Nishimura Y, Kinou M, Kawasaki S, Kasai K. Reduced but broader prefrontal activity in patients with schizophrenia during n-back working memory tasks: a multi-channel near-infrared spectroscopy study. JPsychiatr Res (2013) 47(9):1240-6. doi:10.1016/j.jpsychires.2013.05.009

67. Nishimura Y, Takizawa R, Muroi M, Marumo K, Kinou M, Kasai K. Prefrontal cortex activity during response inhibition associated with excitement symptoms in schizophrenia. Brain Res (2011) 1370:194-203. doi:10.1016/j.brainres. 2010.11.003

68. Watanabe A, Kato T. Cerebrovascular response to cognitive tasks in patients with schizophrenia measured by near-infrared spectroscopy. Schizophr Bull (2004) 30:435-44. doi:10.1093/oxfordjournals.schbul.a007090

69. Quaresima V, Giosue P, Roncone R, Casacchia M, Ferrari M. Prefrontal cortex dysfunction during cognitive tests evidenced by functional near-infrared spectroscopy. Psychiatry Res (2009) 171:252-7. doi:10.1016/j.pscychresns.2008.02. 002

70. Azechi M, Iwase M, Ikezawa K, Takahashi H, Canuet L, Kurimoto R, et al. Discriminant analysis in schizophrenia and healthy subjects using prefrontal activation during frontal lobe tasks: a near-infrared spectroscopy. Schizophr Res (2010) 117:52-60. doi:10.1016/j.schres.2009.10.003

71. Ikezawa K, Iwase M, Ishii R, Azechi M, Canuet L, Ohi K, et al. Impaired regional hemodynamic response in schizophrenia during multiple prefrontal activation tasks: a two-channel near-infrared spectroscopy study. Schizophr Res (2009) 108:93-103. doi:10.1016/j.schres.2008.12.010

72. Takeshi K, Nemoto T, Fumoto M, Arita H, Mizuno M. Reduced prefrontal cortex activation during divergent thinking in schizophrenia: a multi-channel NIRS study. Prog Neuropsychopharmacol Biol Psychiatry (2010) 34:1327-32. doi:10.1016/j.pnpbp.2010.07.021

73. Shimodera S, Imai Y, Kamimura N, Morokuma I, Fujita H, Inoue S, et al. Mapping hypofrontality during letter fluency task in schizophrenia: a multichannel near-infrared spectroscopy study. Schizophr Res (2012) 136:63-9. doi:10.1016/j.schres.2012.01.039

74. Ehlis AC, Herrmann MJ, Plichta MM, Fallgatter AJ. Cortical activation during two verbal fluency tasks in schizophrenic patients and healthy controls as assessed by multi-channel near-infrared spectroscopy. Psychiatry Res (2007) 156:1-13. doi:10.1016/j.pscychresns.2006.11.007

75. Kubota Y, Toichi M, Shimizu M, Mason RA, Coconcea CM, Findling RL, et al. Prefrontal activation during verbal fluency tests in schizophrenia a near-infrared spectroscopy (NIRS) study. Schizophr Res (2005) 77:65-73. doi:10.1016/j.schres.2005.01.007

76. Tupak SV, Badewien M, Dresler T, Hahn T, Ernst LH, Herrmann MJ, et al. Differential prefrontal and frontotemporal oxygenation patterns during phonemic and semantic verbal fluency. Neuropsychologia (2012) 50:1565-9. doi:10.1016/j.neuropsychologia.2012.03.009

77. Anonymous. First do no harm. Nature (2011) 469:132. doi:10.1038/469132a

78. Cyranoski D. Neuroscience: thought experiment. Nature (2011) 469:148-9. doi:10.1038/469148a

79. Shinba T, Nagano M, Kariya N, Ogawa K, Shinozaki T, Shimosato S, et al. Nearinfrared spectroscopy analysis of frontal lobe dysfunction in schizophrenia Biol Psychiatry (2004) 55:154-64. doi:10.1016/S0006-3223(03)00547-X

80. Hoshi Y, Shinba T, Sato C, Doi N. Resting hypofrontality in schizophrenia: a study using near-infrared time-resolved spectroscopy. Schizophr Res (2006) 84:411-20. doi:10.1016/j.schres.2006.03.010

81. Koike S, Takizawa R, Nishimura Y, Marumo K, Kinou M, Kawakubo Y, et al. Association between severe dorsolateral prefrontal dysfunction during random number generation and earlier onset in schizophrenia. Clin Neurophysiol (2011) 122:1533-40. doi:10.1016/j.clinph.2010.12.056

82. Fallgatter AJ, Strik WK. Reduced frontal functional asymmetry in schizophrenia during a cued continuous performance test assessed with near-infrared spectroscopy. Schizophr Bull (2000) 26:913-9. doi:10.1093/oxfordjournals. schbul.a033505

83. Folley BS, Park S. Verbal creativity and schizotypal personality in relation to prefrontal hemispheric laterality: a behavioral and near-infrared optical imaging study. Schizophr Res (2005) 80:271-82. doi:10.1016/j.schres.2005.06.016

84. Zhu Y, Liu X, Wang H, Jiang T, Fang Y, Hu H, et al. Reduced prefrontal activation during tower of London in first-episode schizophrenia: a multi-channel 
near-infrared spectroscopy study. Neurosci Lett (2010) 478:136-40. doi:10. 1016/j.neulet.2010.05.003

85. Taniguchi K, Sumitani S, Watanabe Y, Akiyama M, Ohmori T. Multi-channel near-infrared spectroscopy reveals reduced prefrontal activation in schizophrenia patients during performance of the kana Stroop task. J Med Invest (2012) 59:45-52. doi:10.2152/jmi.59.45

86. Fujita Y, Takebayashi M, Hisaoka K, Tsuchioka M, Morinobu S, Yamawaki S. Asymmetric alternation of the hemodynamic response at the prefrontal cortex in patients with schizophrenia during electroconvulsive therapy: a nearinfrared spectroscopy study. Brain Res (2011) 1410:132-40. doi:10.1016/j. brainres.2011.06.052

87. Purcell SM, Wray NR, Stone JL, Visscher PM, O'Donovan MC, Sullivan PF, et al. Common polygenic variation contributes to risk of schizophrenia and bipolar disorder. Nature (2009) 460:748-52. doi:10.1038/nature08185

88. Shi JX, Levinson DF, Duan JB, Sanders AR, Zheng YL, Pe'er I, et al. Common variants on chromosome $6 \mathrm{p} 22.1$ are associated with schizophrenia. Nature (2009) 460:753-7. doi:10.1038/nature08192

89. Takizawa R, Tochigi M, Kawakubo Y, Marumo K, Sasaki T, Fukuda M, et al. Association between catechol-O-methyltrasferase Val108/158Met genotype and prefrontal hemodynamic response in schizophrenia. PLoS One (2009) 4:e5495. doi:10.1371/journal.pone.0005495

90. Takizawa R, Hashimoto K, Tochigi M, Kawakubo Y, Marumo K, Sasaki T, et al. Association between sigma-1 receptor gene polymorphism and prefrontal hemodynamic response induced by cognitive activation in schizophrenia. Prog Neuropsychopharmacol Biol Psychiatry (2009) 33:491-8. doi:10.1016/j.pnpbp. 2009.01.014

91. Ohi K, Hashimoto R, Yasuda Y, Fukumoto M, Yamamori H, Umeda-Yano S, et al. The SIGMAR1 gene is associated with a risk of schizophrenia and activation of the prefrontal cortex. Prog Neuropsychopharmacol Biol Psychiatry (2011) 35:1309-15. doi:10.1016/j.pnpbp.2011.04.008

92. Ohi K, Hashimoto R, Yasuda Y, Kiribayashi M, Iike N, Yoshida T, et al. TATA box-binding protein gene is associated with risk for schizophrenia, age at onset and prefrontal function. Genes Brain Behav (2009) 8:473-80. doi:10.1111/j.1601-183X.2009.00497.x

93. Reif A, Schecklmann M, Eirich E, Jacob CP, Jarczok TA, Kittel-Schneider S, et al. A functional promoter polymorphism of neuronal nitric oxide synthase moderates prefrontal functioning in schizophrenia. Int J Neuropsychopharmacol (2011) 14:887-97. doi:10.1017/S1461145710001677

94. Koutsouleris N, Meisenzahl EM, Davatzikos C, Bottlender R, Frodl T, Scheuerecker J, et al. Use of neuroanatomical pattern classification to identify subjects in at-risk mental states of psychosis and predict disease transition. Arch Gen Psychiatry (2009) 66:700-12. doi:10.1001/archgenpsychiatry. 2009.62

95. Kohmura K, Iwamoto K, Aleksic B, Sasada K, Kawano N, Katayama H, et al. Effects of sedative antidepressants on prefrontal cortex activity during verbal fluency task in healthy subjects: a near-infrared spectroscopy study. Psychopharmacology (Berl) (2013) 226:75-81. doi:10.1007/s00213-012-2885-8
96. Koike S, Takano Y, Iwashiro N, Satomura Y, Suga M, Nagai T, et al. A multimodal approach to investigate biomarkers for psychosis in a clinical setting: the integrative neuroimaging studies in schizophrenia targeting for early intervention and prevention (IN-STEP) project. Schizophr Res (2013) 143:116-24. doi:10.1016/j.schres.2012.11.012

97. Mihara M, Miyai I, Hattori N, Hatakenaka M, Yagura H, Kawano T, et al. Neurofeedback using real-time near-infrared spectroscopy enhances motor imagery related cortical activation. PLoS One (2012) 7:e32234. doi:10.1371/journal. pone. 0032234

98. Nishida A, Tanii H, Nishimura Y, Kajiki N, Inoue K, Okada M, et al. Associations between psychotic-like experiences and mental health status and other psychopathologies among Japanese early teens. Schizophr Res (2008) 99:125-33. doi:10.1016/j.schres.2007.11.038

99. Suda M, Takei Y, Aoyama Y, Narita K, Sato T, Fukuda M, et al. Frontopolar activation during face-to-face conversation: an in situ study using near-infrared spectroscopy. Neuropsychologia (2010) 48:441-7. doi:10.1016/j. neuropsychologia.2009.09.036

100. Tomioka H, Yamagata B, Takahashi T, Yano M, Isomura AJ, Kobayashi H, et al. Detection of hypofrontality in drivers with Alzheimer's disease by near-infrared spectroscopy. Neurosci Lett (2009) 451(3):252-6. doi:10.1016/j.neulet.2008.12. 059

101. Ye JC, Tak S, Jang KE, Jung J, Jang J. NIRS-SPM: statistical parametric mapping for near-infrared spectroscopy. Neuroimage (2009) 44:428-47. doi:10.1016/j. neuroimage.2008.08.036

102. Cristia A, Dupoux E, Hakuno Y, Lloyd-Fox S, Schuetze M, Kivits J, et al. An online database of infant functional near infrared spectroscopy studies: a community-augmented systematic review. PLoS One (2013) 8:e58906. doi:10.1371/journal.pone.0058906

Conflict of Interest Statement: The authors declare that the research was conducted in the absence of any commercial or financial relationships that could be construed as a potential conflict of interest.

Received: 01 September 2013; accepted: 25 October 2013; published online: 14 November 2013.

Citation: Koike S, Nishimura Y, Takizawa R, Yahata N and Kasai K (2013) Nearinfrared spectroscopy in schizophrenia: a possible biomarker for predicting clinical outcome and treatment response. Front. Psychiatry 4:145. doi: 10.3389/fpsyt.2013.00145 This article was submitted to Schizophrenia, a section of the journal Frontiers in Psychiatry.

Copyright (c) 2013 Koike, Nishimura, Takizawa, Yahata and Kasai. This is an openaccess article distributed under the terms of the Creative Commons Attribution License (CC BY). The use, distribution or reproduction in other forums is permitted, provided the original author(s) or licensor are credited and that the original publication in this journal is cited, in accordance with accepted academic practice. No use, distribution or reproduction is permitted which does not comply with these terms. 